Journal for ImmunoTherapy of Cancer

\title{
Prognostic significance and immune correlates of CD73 expression in renal cell carcinoma
}

\author{
Abhishek Tripathi (D) ,1,2 Edwin Lin, ${ }^{3}$ Wanling Xie, ${ }^{4}$ Abdallah Flaifel, ${ }^{5}$ \\ John A Steinharter, ${ }^{2}$ Emily N Stern Gatof, ${ }^{6}$ Gabrielle Bouchard, ${ }^{2}$ Justin H Fleischer, ${ }^{2}$ \\ Nieves Martinez-Chanza (D) ,2 Connor Gray, ${ }^{6}$ Charlene Mantia, ${ }^{6}$ Linda Thompson, ${ }^{7}$ \\ Xiao X Wei, ${ }^{2}$ Marios Giannakis, ${ }^{8}$ Bradley A McGregor, ${ }^{2}$ Toni K Choueiri (1) , ${ }^{2}$ \\ Neeraj Agarwal (1) , ${ }^{3}$ David F McDermott, ${ }^{6}$ Sabina Signoretti, ${ }^{5}$ \\ Lauren C Harshman (iD ${ }^{2}$
}

To cite: Tripathi A, Lin E, Xie W, et al. Prognostic significance and immune correlates of CD73 expression in renal cell carcinoma. Journal for ImmunoTherapy of Cancer 2020;8:e01467. doi:10.1136/ jitc-2020-001467

- Additional material is published online only. To view, please visit the journal online (http://dx.doi.org/10.1136/jitc2020-001467).

AT and EL are joint first authors. Accepted 02 October 2020

Check for updates

(C) Author(s) (or their employer(s)) 2020. Re-use permitted under CC BY. Published by BMJ.

For numbered affiliations see end of article.

Correspondence to Dr Lauren C Harshman; Icharshman@gmail.com

\section{ABSTRACT}

Background CD73-adenosine signaling in the tumor microenvironment is immunosuppressive and may be associated with aggressive renal cell carcinoma (RCC). We investigated the prognostic significance of CD73 protein expression in RCC leveraging nephrectomy samples. We also performed a complementary analysis using The Cancer Genome Atlas (TCGA) dataset to evaluate the correlation of CD73 (ecto-5'-nucleotidase (NT5E), CD39 (ectonucleoside triphosphate diphosphohydrolase 1 (ENTPD1)) and A2 adenosine receptor (A2AR; ADORA2A) transcript levels with markers of angiogenesis and antitumor immune response.

Methods Patients with RCC with available archived nephrectomy samples were eligible for inclusion. Tumor CD73 protein expression was assessed by immunohistochemistry and quantified using a combined score (CS: \% positive cells $\times$ intensity). Samples were categorized as $\mathrm{CD7} 3_{\text {negative }}$ (CS=0), $C D 73_{\text {low }}$ or $\mathrm{CD7} 3_{\text {high }}$ ( $<$ and $\geq$ median CS, respectively). Multivariable Cox regression analysis compared disease-free survival (DFS) and overall survival (OS) between CD73 expression groups. In the TCGA dataset, samples were categorized as low, intermediate and high NT5E, ENTPD1 and ADORA2A gene expression groups. Gene expression signatures for infiltrating immune cells, angiogenesis, myeloid inflammation, and effector T-cell response were compared between NT5E, ENTPD1 and ADORA2A expression groups. Results Among the 138 patients eligible for inclusion, 'any' CD73 expression was observed in 30\% of primary tumor samples. High CD73 expression was more frequent in patients with M1 RCC ( $29 \%$ vs $12 \% \mathrm{M} 0)$, grade 4 tumors ( $27 \%$ vs $13 \%$ grade 3 vs $15 \%$ grades 1 and 2$)$, advanced T-stage ( $\geq \mathrm{T} 3: 22 \%$ vs T2: $19 \%$ vs $\mathrm{T} 1: 12 \%$ ) and tumors with sarcomatoid histology ( $50 \%$ vs $12 \%)$. In the M0 cohort $(n=107)$, patients with $C D 73_{\text {high }}$ tumor expression had significantly worse 5 -year DFS (42\%) and 10 -year OS (22\%) compared with those in the CD73 group (DFS: $75 \%$, adjusted HR: $2.7,95 \% \mathrm{Cl} 1.3$ to 5.9 , $\mathrm{p}=0.01$; 0S: $64 \%$, adjusted HR: $2.6,95 \% \mathrm{Cl} 1.2$ to 5.8 , $\mathrm{p}=0.02$ ) independent of tumor stage and grade. In the TCGA analysis, high NT5E expression was associated with significantly worse 5 -year OS $(p=0.008)$. NT5E and ENTPD1 expression correlated with higher regulatory
T cell (Treg) signature, while ADORA2A expression was associated with increased Treg and angiogenesis signatures.

Conclusions High CD73 expression portends significantly worse survival outcomes independent of stage and grade. Our findings provide compelling support for targeting the immunosuppressive and proangiogenic CD73-adenosine pathway in RCC.

\section{INTRODUCTION}

Immune checkpoint inhibitors targeting the programmed cell death-1 (PD-1) and cytotoxic T-lymphocyte-associated antigen-4 (CTLA-4) pathways have significantly advanced the treatment of metastatic renal cell carcinoma (mRCC). Recent studies combining PD-1/L1 inhibitors with either the vascular endothelial growth factor (VEGF) receptor tyrosine kinase inhibitor axitinib or the anti-CTLA-4 antibody ipilimumab have demonstrated improved objective response rates (ORRs), progression-free survival (PFS) and overall survival (OS) compared with sunitinib. ${ }^{1-4}$ Given these results, most patients with clear cell renal cell carcinoma (ccRCG) will receive a PD-1/L1 inhibitor-based regimen either in combination with axitinib or, if intermediate or poor-risk disease, ipilimumab, as firstline therapy. Although immune checkpoint blockade represents a significant therapeutic advance, approximately $20 \%$ of patients are primary treatment-refractory to these agents, and the majority who experience clinical benefit eventually progress as evidenced by a median PFS of 12-14 months on any of these regimens. ${ }^{1-4}$ The lack of response in a significant proportion of patients and eventual disease progression in most patients suggests the existence of multiple non-redundant mechanisms of de novo or acquired 
resistance to immune checkpoint inhibition in the tumor microenvironment.

CD73 (ecto-5'-nucleotidase $(N T 5 E)$ ) and CD39 (ectonucleoside triphosphate diphosphohydrolase 1 (ENTPD1)) mediate sequential dephosphorylation of extracellular ATP to adenosine with CD73 catalyzing the rate-limiting step. ${ }^{5}$ A hypoxic tumor microenvironment significantly increases CD73 expression on tumor cells and tumor-infiltrating immune cells through hypoxiainducible factor (HIF)-1 $1 \alpha^{6-8}$ Adenosine generated by CD73 and CD39 binds to and activates $G$ protein-coupled A1, A2A, A2B, and A3 receptors. ${ }^{9}$ In preclinical models, increased adenosine signaling attenuates the antitumor immune response through the proliferation of regulatory $\mathrm{T}$ cells (Tregs) and myeloid-derived suppressor cells (MDSCs) and differentiation of tumor-associated macrophages into the immunosuppressive M2 phenotype. ${ }^{10-13}$ Adenosine signaling may also stimulate angiogenesis through increased vasodilation, release of proangiogenic factors such as VEGF, and recruitment of endothelial progenitor cells in the tumor microenvironment. ${ }^{14-16}$

Previously, our group found that CD73 was more frequently expressed in mRCC specimens compared with primary tumors. ${ }^{17}$ As $\mathrm{CD} 73$ mediates the rate-limiting step in the generation of immunosuppressive adenosine, we hypothesized that higher $\mathrm{CD} 73$ expression correlates with more aggressive disease in renal cell carcinoma (RCC). Employing an institutional dataset of RCC samples, we investigated the prognostic significance of CD73 expression in localized RCC. Using gene expression data from The Cancer Genome Atlas (TCGA) Kidney Renal Clear Cell Carcinoma (KIRC) dataset, we also evaluated the correlation of mRNA expression of CD73 (NT5E), CD39 (ENTPD1) and A2AR (ADORA2A) with gene expression signatures reflecting angiogenesis, myeloid inflammation and effector T-cell response $\left(\mathrm{T}_{\text {eff }}\right)$ and infiltrating immune cell subsets.

\section{METHODS}

\section{Institutional dataset}

The study used previously established RCC tissue microarrays (TMAs) which included primary tumor samples from patients with localized or de novo mRCC (T1-4, N0-1, M0-1), who underwent nephrectomy at Dana-Farber Cancer Institute/Brigham and Women's Hospital and Beth Israel Deaconess Medical Center between January 2002 and May 2006. Immunohistochemistry (IHC) for CD73 was performed on the formalin-fixed paraffinembedded tumor tissue from the TMAs. Rehydrated tissue sections were boiled in citrate buffer $\mathrm{pH}$ 6.0 (Life Technologies, Frederick, Maryland, USA) with a pressure cooker (Biocare Medical, Pacheco, California, USA) for $30 \mathrm{~s}$ at $125^{\circ} \mathrm{C}$. After cooling down at room temperature (RT), tissue sections were successively incubated with a peroxidase block (Dual Endogenous Enzyme Block, Agilent) and a protein block (Serum Free Block, Agilent) for 10 min each. Sections were next incubated for 1 hour at RT with the rabbit monoclonal anti-CD73 antibody (clone D7F9A, 1:25; Cell Signaling Technology) diluted in antibody diluent with background reducing components (Agilent). Tissue sections were then incubated for 1 hour at RT with a polyclonal mouse anti-rabbit antibody (Agilent, 1:750) diluted in antibody diluent with background reducing components (Agilent) followed by incubation for 30 min at RT with EnVision anti-mouse horseradish peroxidase (HRP)-conjugated antibody (Agilent). HRP visualization was performed by applying 3,3-diaminobenzidine+substrate (Agilent) for $1 \mathrm{~min}$ and $30 \mathrm{~s}$. Between steps, tissue sections were washed for $5 \mathrm{~min}$ in washing buffer ( $0.1 \mathrm{mM}$ Tris, $\mathrm{pH} 7.4+0.05 \%$ Tween 20$)$. Nuclei were counterstained with hematoxylin.

von Hippel-Lindau deficient and proficient University of Michigan-Renal Carcinoma-2 cells were used as positive and negative controls, respectively. Percentage of cell staining positive for CD73 and the intensity of staining (1+, $2+$ or $3+$ ) were assessed manually by one observer (SS). CD73 expression for each sample was quantified using a combined score (CS), which was calculated by multiplying the intensity of staining $(1+, 2+$, or $3+)$ with the percentage of tumor cells staining positive. For patients with multiple tumor samples with evaluable CD73 expression, the mean CS of all available samples was calculated. CD73 positivity was defined as any CD73 expression on tumor cells irrespective of percentage of cells or the intensity of staining. Patients with CD73 positivity were categorized into $\mathrm{CD} 73_{\text {low }}$ and $\mathrm{CD} 73_{\text {high }}$ subgroups. Patients with CS less than the median CS of all CD73-positive patients were designated as $\mathrm{CD} 73_{\text {low }}$. Conversely, those with expression equal to or higher than the median CS were characterized as CD73 $3_{\text {high }}$. Clinical and pathological characteristics such as tumor stage, Fuhrman grade, presence or absence of sarcomatoid features, along with outcomes data, were cataloged through retrospective chart review by investigators blinded to the $\mathrm{CD} 73$ expression data.

\section{TCGA dataset}

RNA-seq data for 538 ccRCC samples derived from primary tumors were obtained from the TCGA-KIRC dataset. ${ }^{18}$ Gene expression of CD73 (NT5E), CD39 (ENTPD1) and A2AR (ADORA2A) was quantified by HT-seq and measured in upper-quartile normalized fragments per kilobase million. ${ }^{19}$ Patients were split into low ( $\leq-1 \mathrm{SD}$ from the overall mean), intermediate ( -1 to 1 SD from the mean), and high ( $\geq 1$ SD from the mean) NT5E, ENTPD1 and ADORA2A expression groups. Averaged $\log 2$-transformed expression of previously validated genes was used to calculate angiogenesis (VEGFA, KDR, ESM1, PECAM1, ANGPTL4 and CD34), myeloid inflammation (IL-6, CXCL1, CXCL2, CXCL3, CXCL8 and PTGS2), and $\mathrm{T}_{\text {eff }}$ (CD8A, EOMES, PRF1, IFNG and CD274) gene expression signatures. ${ }^{20}$ Gene signatures for tumor-infiltrating immune cells such as B cells, $\mathrm{CD} 4^{+} \mathrm{T}$ cells, $\mathrm{CD}^{+} \mathrm{T}$ cells, neutrophils, NK cells, macrophages, and dendritic cells were calculated based on averaged 
Table 1 Baseline characteristics of patients $(\mathrm{N}=138)$

\begin{tabular}{|c|c|c|}
\hline $\begin{array}{l}\text { Localized } \\
\text { RCC } \\
(\mathrm{N}=107)\end{array}$ & $\begin{array}{l}\text { De novo } \\
\text { mRCC } \\
(\mathrm{N}=31)\end{array}$ & $\begin{array}{l}\text { Total } \\
\text { ( } \mathrm{N=138)}\end{array}$ \\
\hline$\%$ & n $\%$ & $\mathrm{n}$ \\
\hline
\end{tabular}

\begin{tabular}{|c|c|c|c|c|c|c|}
\hline \multicolumn{7}{|l|}{ Gender } \\
\hline Female & 43 & 40 & 14 & 45 & 57 & 41 \\
\hline Male & 64 & 60 & 17 & 55 & 81 & 59 \\
\hline \multicolumn{7}{|l|}{ Histology } \\
\hline ccRCC & 78 & 73 & 25 & 81 & 103 & 75 \\
\hline nccRCC & 28 & 26 & 5 & 16 & 33 & 24 \\
\hline Chromophobe & 14 & 13 & . & & 14 & 10 \\
\hline $\begin{array}{l}\text { Papillary not } \\
\text { subtyped }\end{array}$ & 6 & 6 & 1 & 3 & 7 & 5 \\
\hline
\end{tabular}

\begin{tabular}{|lrrrrrr|}
\hline Papillary type 1 & 4 & 4 & 1 & 3 & 5 & 4 \\
\hline Papillary type 2 & 3 & 3 & 1 & 3 & 4 & 3 \\
\hline $\begin{array}{l}\text { RCC } \\
\text { unclassified }\end{array}$ & 1 & 1 & 2 & 7 & 3 & 2 \\
\hline $\begin{array}{l}\text { Unknown } \\
\text { Pathological T }\end{array}$ & 1 & 1 & 1 & 3 & 2 & 1 \\
stage & & & & & & \\
\hline T1 & 58 & 54 & 2 & 6 & 60 & 44 \\
\hline T2 & 21 & 20 & 7 & 23 & 28 & 20 \\
\hline T3 & 21 & 20 & 21 & 68 & 42 & 30 \\
\hline T4 & 3 & 3 & 1 & 3 & 4 & 3 \\
\hline Unknown & 4 & 4 &. &. & 4 & 3 \\
\hline $\begin{array}{l}\text { Pathological N } \\
\text { stage }\end{array}$ & & & & & & \\
\hline N0 & 33 & 31 & 11 & 36 & 44 & 32 \\
\hline N1 & 8 & 8 & 6 & 19 & 14 & 10 \\
\hline Nx & 62 & 58 & 14 & 45 & 76 & 55 \\
\hline Unknown & 4 & 4 &. &. & 4 & 3 \\
\hline AJCC stage & & & & & & \\
\hline I & 57 & 53 &. &. & 57 & 41 \\
\hline II & 19 & 18 &. &. & 19 & 14 \\
\hline III (T3 or N1) & 26 & 24 &. &. & 26 & 19 \\
\hline IV (T4 or M1) & 3 & 3 & 31 & 100 & 34 & 25 \\
\hline Unknown & 2 & 2 &. &. & 2 & 1 \\
\hline Funn grade & & & & & & \\
\hline
\end{tabular}

Fuhrman grade

$\begin{array}{lrrrrrr}\text { G1 } & 7 & 7 & . & . & 7 & 5 \\ \text { G2 } & 59 & 55 & 9 & 29 & 68 & 49 \\ \text { G3 } & 26 & 24 & 12 & 39 & 38 & 28 \\ \text { G4 } & 13 & 12 & 9 & 29 & 22 & 16 \\ \text { Unknown } & 2 & 2 & 1 & 3 & 3 & 2\end{array}$

Sarcomatoid

features

\begin{tabular}{lrrrrrr} 
No & 100 & 94 & 24 & 77 & 124 & 90 \\
Yes & 4 & 4 & 6 & 19 & 10 & 7 \\
Unknown & 3 & 3 & 1 & 3 & 4 & 3 \\
\hline
\end{tabular}

Table 1 Continued

\begin{tabular}{|c|c|c|}
\hline $\begin{array}{l}\text { Localized } \\
\text { RCC } \\
(\mathrm{N}=107)\end{array}$ & $\begin{array}{l}\text { De novo } \\
\text { mRCC } \\
(\mathrm{N}=31)\end{array}$ & $\begin{array}{l}\text { Total } \\
\text { (N=138) }\end{array}$ \\
\hline$\%$ & $\%$ & $\mathbf{n}$ \\
\hline
\end{tabular}

\begin{tabular}{lrrrrrr}
\hline Adjuvant therapy & & & & & & \\
No & 103 & 96 & 31 & 100 & 134 & 97 \\
Yes & 3 & 3 &. &. & 3 & 2 \\
Unknown & 1 & 1 &. &. & 1 & 1 \\
\hline
\end{tabular}

AJCC, American Joint Committee on Cancer; ccRCC, clear cell renal cell carcinoma; mRCC, metastatic renal cell carcinoma; nccRCC, non-clear cell renal cell carcinoma; RCC, renal cell carcinoma.

log-transformed expression levels of previously validated immune metagenes. ${ }^{21}$

\section{Statistical analysis}

Baseline patient characteristics were summarized using descriptive statistics. The distribution of CD73 expression in the primary tumor $\left(\mathrm{CD} 73_{\text {negative }}\right.$ vs $\mathrm{CD} 73_{\text {low }}$ or $\left.\mathrm{CD} 73_{\text {high }}\right)$ by baseline clinical and pathologic characteristics was compared using the Cochran-Armitage Trend test (for variables with two categories) and Jonckheere-Terpstra test (for variables three or more ordered categories). The primary survival analysis focused on patients with localized RCC for which disease-free survival (DFS) and OS were primary outcome measures. DFS was defined as the time from nephrectomy to disease recurrence or death from any cause. OS was defined as the time from nephrectomy to death from any cause. DFS and OS were censored at the date of the last follow-up. An exploratory analysis evaluated outcomes between CD73 expression groups in patients with de novo mRCC. For this analysis, OS was the primary outcome measure and defined as the time from cytoreductive nephrectomy to death from any cause. Distribution of DFS and OS were estimated using the Kaplan Meier method. Multivariable Cox regression analysis was used to estimate the association of CD73 expression with DFS and OS adjusted for known prognostic factors tumor grade (grade $\geq 3 \mathrm{vs}<3$ ) and the American Joint Committee on Cancer (AJCC) disease stage (III/IV vs I/II). All statistical tests were two-sided and statistical significance was considered at $\mathrm{p}<0.05$.

In the TCGA dataset, the Mann-Whitney $U$ test was used to compare AJCC disease stage and gene expression signature scores between low, intermediate, and high NT5E, ENTPD1 and ADORA2A expression groups. Bonferroni correction was used to control false discovery rate to $\alpha<0.05$. Significant differences were defined by a fold change $>4$ and adjusted $\mathrm{p}<0.05$. OS was compared between low, intermediate, and high NT5E and ADORA2A groups using the Log rank test stratified by AJCC stage. All bioinformatic analyzes and figures using TCGA data were produced using Pandas, NumPy, SciPy, and Matplotlib software packages in a Python 3.6 environment. 


\section{RESULTS}

\section{CD73 expression and outcomes in the Dana-Farber/Harvard Cancer Center institutional dataset}

We interrogated TMAs consisting of tumor samples from 199 patients with localized or de novo mRCG. For our analysis, patients were excluded if pathologic diagnosis was not RCC ( $\mathrm{n}=17)$, they had unevaluable CD73 expression $(n=13)$, or there was inadequate linked clinical and pathological data $(\mathrm{n}=19)$ (online supplemental figure 1). In order to minimize potential heterogeneity induced by higher CD73 expression in metastatic samples compared with primary tumors, ${ }^{17}$ we excluded patients who only had samples from metastatic sites $(n=12)$. Of the 138 eligible patients with primary tumor samples, 107 patients had localized RCC, and 31 patients had de novo mRCC. ccRCC was the most common histologic subtype (75\%, $\mathrm{n}=103$; table 1 ) with $24 \%$ non-clear cell disease (papillary, $\mathrm{n}=16$; chromophobe, $\mathrm{n}=14)$. High nuclear grade $(\geq 3)$ and sarcomatoid component was present in $43 \%(\mathrm{n}=60)$ and $7 \%(\mathrm{n}=10)$ respectively. The majority $(\mathrm{n}=88,64 \%)$ had pT1-T2 tumors while $33 \%(\mathrm{n}=46)$ were $\geq \mathrm{pT} 3$ and $10 \%$ had nodal involvement $(\mathrm{n}=14)$. Locally advanced disease defined as AJCC stage III or IV was present in $44 \%(n=60)$ of patients.

In the overall cohort $(\mathrm{n}=138)$, any CD73 expression $(\mathrm{CS}>0)$ was seen in $30 \%(\mathrm{n}=42$, table 2$)$ of samples with a median CS of 11.8 (range 0.1-210, figure 1). In patients with ccRCC, CD73 positivity was seen in $27 \%$ of tumors (median CS: 6.3, range 0.1-125) and 13\% had high CD73 expression. In patients with non-clear cell histology, CD73 positivity was observed in $39 \%$ with $24 \%$ being $\mathrm{CD} 73_{\text {high }}$. Compared with patients with localized (M0) RCC, those with de novo mRCC were more likely to be $\mathrm{CD} 73$ positive (55\% vs 23\%; $\mathrm{p}=0.002$ ) and have high CD73 expression (29\% vs $12 \%$, figure $2, \mathrm{p}=0.002$ ). Similarly, high CD73 expression was more frequent in grade four tumors (27\%) compared with grade $3(13 \%)$ or grade $1-2$ $\left(15 \%, \mathrm{p}_{\text {trend }}=0.035\right.$, figure 2$)$, pathologic stage $\geq \mathrm{T} 3(22 \%)$ compared with T2 $(19 \%)$ and T1 $\left(12 \% ; p_{\text {trend }}=0.004\right)$ and locally advanced disease stage (AJCC stage, IV: $29 \%$ vs III: $12 \%$ vs II: $21 \%$ vs I: $9 \%$; $\left.p_{\text {trend }}<0.0001\right)$. In tumors with sarcomatoid features $(n=10), 90 \%(n=9)$ had any $C D 73$ expression with $50 \%(\mathrm{n}=5)$ being $\mathrm{CD} 73_{\text {high }}$. In contrast, in tumors without sarcomatoid features, only $24 \%(n=30)$ demonstrated any CD73 expression and only $12 \%(n=15)$ were CD73 ${ }_{\text {high }}(\mathrm{p}<0.001)$.

Median follow-up was 10 years (range $<0.1-15.5$ years) for patients with localized RCC $(n=107)$. DFS at 5 years for patients in the $\mathrm{CD} 73_{\text {negative, }}$ CD73 $3_{\text {low }}$ and $\mathrm{CD} 73_{\text {high }}$ groups was $75 \%, 50 \%$ and $42 \%$, respectively (figure $3 \mathrm{~A}$ ). On multivariable analysis adjusting for Fuhrman grade (graded 1-2 vs grades 3-4) and AJCC stage (stage I/II vs III/IV), high CD73 expression was associated with a significantly worse DFS (table 3; adjusted HR: 2.72, 95\% CI 1.27 to $5.85, \mathrm{p}=0.01$ ). Similarly, the $\mathrm{CD} 73_{\text {high }}$ group experienced significantly worse 10-year OS compared with the $\mathrm{CD} 73_{\text {negative }}$ group (22\% vs $64 \%$, adjusted HR: 2.59 , $95 \%$ CI 1.15 to $5.84, \mathrm{p}=0.021$; figure $3 \mathrm{~B}$ ). The survival outcomes were not significantly different between the CD73 ${ }_{\text {negative }}$ and $\mathrm{CD} 73_{\text {low }}$ groups (DFS HR: $1.22,95 \% \mathrm{CI}$ 0.50 to 2.98; OS HR: $0.78,95 \%$ CI 0.27 to 2.30 ). Additional analysis combining the CD73 negative and low groups was performed and the significant differences in DFS and OS remained. The adjusted HR for DFS was 2.89 (95\% CI: 1.37 to 6.07, $\mathrm{p}=0.005$ ) and for OS was $2.86(95 \%$ CI 1.30 to $6.29, \mathrm{p}=0.009$ ) in favor of no or low expression $\left(\mathrm{CD} 73_{\text {high }}\right.$ vs $\mathrm{CD} 73_{\text {negative+low }}$ ) (table 3 ). In an exploratory analysis evaluating OS in patients with de novo mRCC $(\mathrm{n}=31)$, there was no statistically significant difference in 2-year OS between patients in the CD73 $3_{\text {negative }}$ (43\%), $\mathrm{CD} 73_{\text {low }}(50 \%)$ and $\mathrm{CD} 73_{\text {high }}$ groups (52\%, online supplemental figure 2; $\mathrm{p}=0.52$ ).

\section{Clinical and genomic correlates of NT5E, ENTPD1 and ADORA2A gene expression in the TCGA dataset}

In the complementary analysis using TCGA RNA-seq data, high NT5E expression was associated with significantly lower 5-year OS compared with intermediate or low $N T 5 E$ expression (figure 4A) in AJCG stage IV tumors. No significant differences in OS were observed between NT5E expression groups in patients with AJCC stage I-III disease (online supplemental figure 3A-C). NT5E expression was similar across AJCC stages (online supplemental figure 3D). Similarly, there was no significant correlation of ADORA2A expression with OS or AJCG disease stage (online supplemental figure 4). Treg gene expression signature was positively correlated with $N T 5 E$, ENTPD1 and ADORA2A expression (figure 4). The angiogenesis gene expression signature positively correlated with ADORA2A (figure 4D) but not NT5E or ENTPD1 expression (online supplemental tables 1-3). $\mathrm{T}_{\text {eff }}$, myeloid inflammation, and other immune cell signatures (eg, $\mathrm{CD}^{+} \mathrm{T}$ cells, B cells, neutrophils, and macrophages) were not significantly different between the low intermediate and high NT5E, ENTPD1 or ADORA2A expression groups.

\section{DISCUSSION}

In this biomarker-based analysis, CD73 protein expression was present in $30 \%$ of all RCC nephrectomy tumor specimens. Higher expression correlated with more aggressive disease as defined by higher Fuhrman nuclear grade, advanced stage at diagnosis, presence of sarcomatoid histology, and in patients with localized RCC, significantly worse DFS and OS. In a complementary analysis using the TCGA gene expression dataset, high NT5E (CD73) gene expression was associated with significantly worse OS in AJCC stage IV tumors. NT5E and ENTPD1 expression correlated with increased expression of immunosuppressive Treg markers, while A2AR (ADORA2A) expression was associated with significantly higher angiogenesis and Treg gene expression signatures.

There is a sparse but growing literature on the prevalence and clinical significance of $\mathrm{CD} 73$ expression in RCC. Yu et al analyzed CD73 expression by IHC in patients with ccRCC, the majority of whom had localized 
Table 2 Associations of CD73 expression with baseline characteristics of patients ( $N=138$

\section{CD73 expression}

Positive ( $\mathrm{N}=42$ )

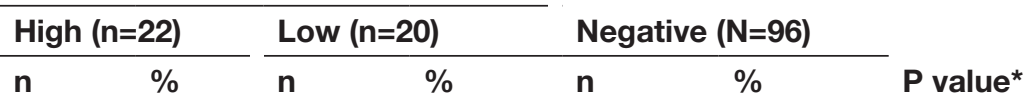

Baseline characteristics (N)

Metastatic status at presentation

Localized RCC $(n=107)$

De novo mRCC $(n=31)$

$13 \quad 12$

$12 \quad 12$

$\begin{array}{ll}11 & 82 \\ 26 & 14\end{array}$

82

Histology

$\begin{array}{lc}\operatorname{ccRCC}(n=103) & 13 \\ \operatorname{nccRCC}(n=33) & 8 \\ \text { Papillary }(n=16) & 6 \\ \text { Chromophobe }(n=14) & 2 \\ \text { RCC unclassified }(n=3) & .\end{array}$

Unknown $(n=2)$

150

77

45

Sarcomatoid features

$\begin{array}{rr}15 & 12 \\ 5 & 50 \\ 2 & 50\end{array}$

13
24
38
14
50

$\begin{array}{rr}15 & 15 \\ 5 & 15 \\ 5 & 31\end{array}$

$\begin{array}{rrr}15 & 75 & 73 \\ 15 & 20 & 61 \\ 31 & 5 & 31 \\ . & 12 & 86 \\ . & 3 & 100 \\ & 1 & 50\end{array}$

No $(n=124)$
Yes $(n=10)$
Unknown $(n=4)$

Fuhrman nuclear grade

\begin{tabular}{|c|c|c|c|c|c|c|c|}
\hline $\mathrm{G} 1-2(\mathrm{n}=75)$ & 11 & 15 & 7 & 9 & 57 & 76 & \\
\hline G3 $(n=38)$ & 5 & 13 & 8 & 21 & 25 & 66 & \\
\hline $\mathrm{G} 4(\mathrm{n}=22)$ & 6 & 27 & 5 & 23 & 11 & 50 & \\
\hline Unknown $(n=3)$ & & & & & 3 & 100 & \\
\hline Pathological T stage & & & & & & & 0.004 \\
\hline $\mathrm{T} 1(\mathrm{n}=60)$ & 7 & 12 & 2 & 3 & 51 & 85 & \\
\hline T2 (n=28) & 5 & 19 & 7 & 25 & 16 & 57 & \\
\hline T3-4 $(n=46)$ & 10 & 22 & 9 & 20 & 27 & 59 & \\
\hline Unknown $(n=4)$ & & & 2 & 50 & 2 & 50 & \\
\hline AJCC stage & & & & & & & $<0.0001$ \\
\hline I $(\mathrm{n}=57)$ & 5 & 9 & 2 & 4 & 50 & 88 & \\
\hline II $(n=19)$ & 4 & 21 & 4 & 21 & 11 & 58 & \\
\hline III $(n=26)$ & 3 & 12 & 4 & 15 & 19 & 73 & \\
\hline IV $(n=34)$ & 10 & 29 & 9 & 27 & 15 & 44 & \\
\hline Unknown $(n=2)$ & & & 1 & 50 & 1 & 50 & \\
\hline
\end{tabular}

${ }^{*}$ Cochran-Armitage Trend test (for variables with two categories) and Jonckheere-Terpstra test (for variables with $\geq 3$ ordered categories); unknown group was excluded from the comparison.

†P value is for comparison of ccRCC versus nccRCC.

AJCC, American Joint Committee on Cancer; ccRCC, clear cell renal cell carcinoma; mRCC, metastatic renal cell carcinoma; nccRCC, nonclear cell renal cell carcinoma; RCC, renal cell carcinoma.

(T1-4, N0, M0) disease. ${ }^{22}$ Nearly half of tumors $(48 \%)$ expressed CD73, which was associated with high tumor grade and $\mathrm{T}$ stage. In our prior work in RCC, we observed CD73 expression in $19 \%$ of primary tumors and that expression was significantly more common in metastatic tumor samples $(67 \%) \cdot{ }^{17} \mathrm{CD} 73$ expression in the primary tumor was associated with a trend towards higher nuclear grade and numerically worse 5-year OS. Our current analysis included tumor samples from 107 patients with localized RCC and 31 patients with de novo mRCC from three high-volume kidney cancer centers with wellannotated long-term clinical outcomes (median 10 years from nephrectomy). Confirming the results of our prior study, tumors from patients with de novo mRCC had a significantly higher propensity to express CD73 (55\%) compared with localized disease $(23 \%, \mathrm{p}=0.002)$. The relatively higher prevalence of CD73 expression demonstrated by Yu et almight be due to different antibodies used 

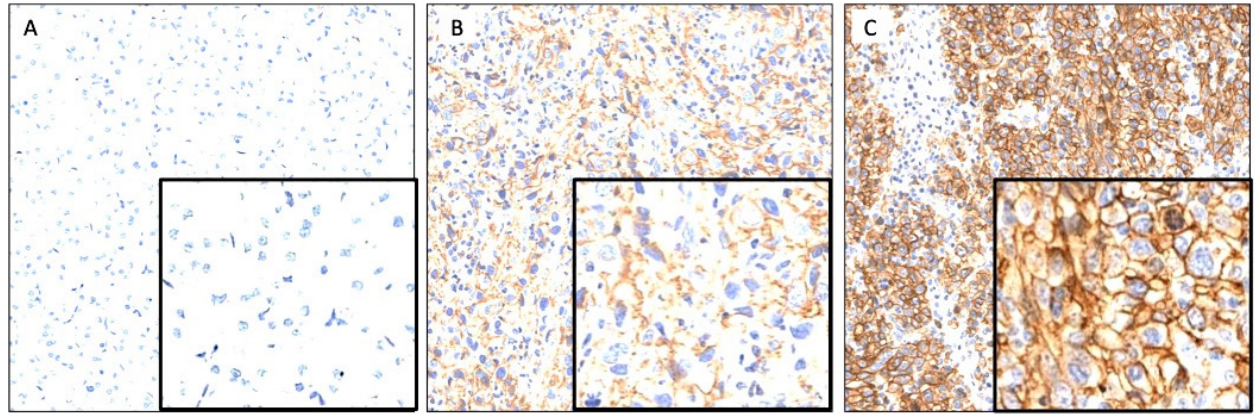

Figure 1 Representative images demonstrating membraneous CD73 expression on tumor cells in the CD73 ${ }_{\text {negative }}(A), C D 73_{\text {low }}$ (B) and CD73 high $(C)$ groups.

for IHC in their analysis (ab115289; Abcam, Cambridge, Massachusetts, USA). The prevalence of CD73 positivity seen in the current analysis is consistent with our prior study using the same anti-CD73 antibody (clone D7F9A, Cell Signaling Technology).

CD73 expression also correlated with adverse pathologic features and was independently associated with worse prognosis after adjusting for other prognostic features such as tumor grade and AJCC stage in patients with localized RCC. Similarly, in the TCGA dataset, high NT5E expression was associated with worse outcomes in patients with AJCC stage IV RCC. These findings suggest Metastatic status:

$$
\text { Localized RCC }(\mathrm{N}=107)
$$

De novo metastatic RCC $(\mathrm{N}=31)$

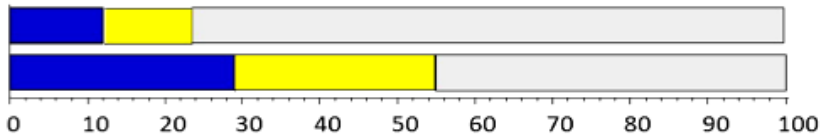

Fuhrman Nuclear grade:

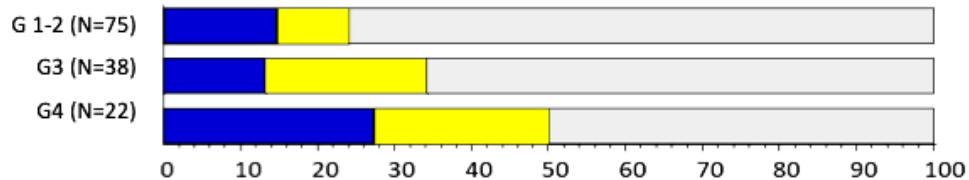

Pathologic T-stage:

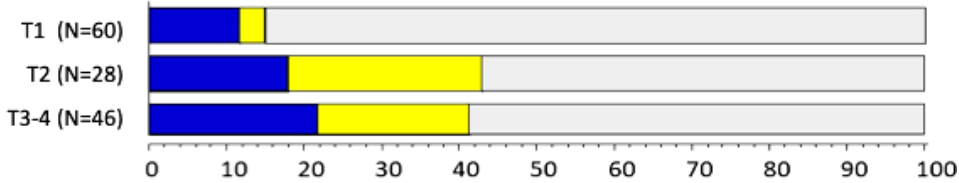

AICC stage:

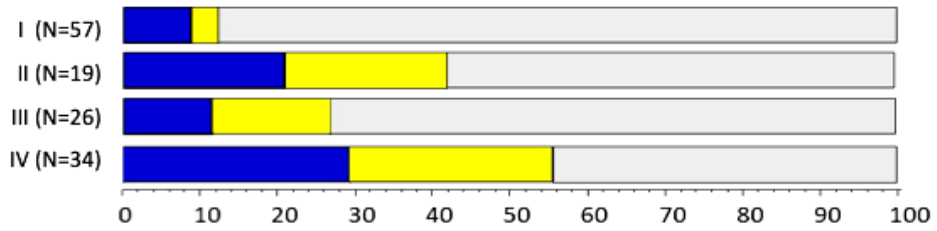

Sarcomatoid features:

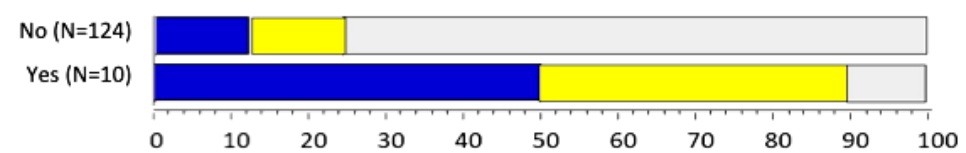

Histology:

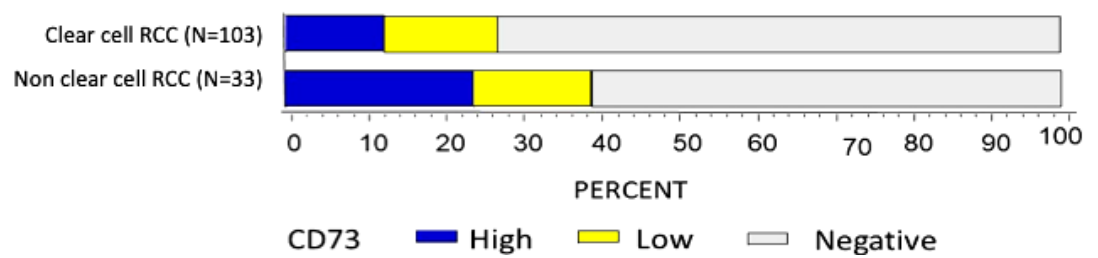

Figure 2 Distribution of CD73 expression (negative, low and high) by baseline clinical and pathological characteristics. AJCC, American Joint Committee on Cancer; RCC, renal cell carcinoma. that CD73-adenosine signaling may be a potential driver of aggressive disease in patients with both localized and advanced RCC. As several agents targeting this pathway are in early clinical development, these findings provide compelling rationale for targeting this pathway not only in mRCC but also as perioperative therapy in patients with localized disease and high CD73 expression.

We also characterized CD73 expression in non-clear cell subtypes (papillary $\mathrm{n}=16$, chromophobe $\mathrm{n}=14$ ) and tumors with a sarcomatoid component $(\mathrm{n}=10)$, RCC disease states where expression of inhibitory immune checkpoints has been shown to play a significant immunosuppressive 


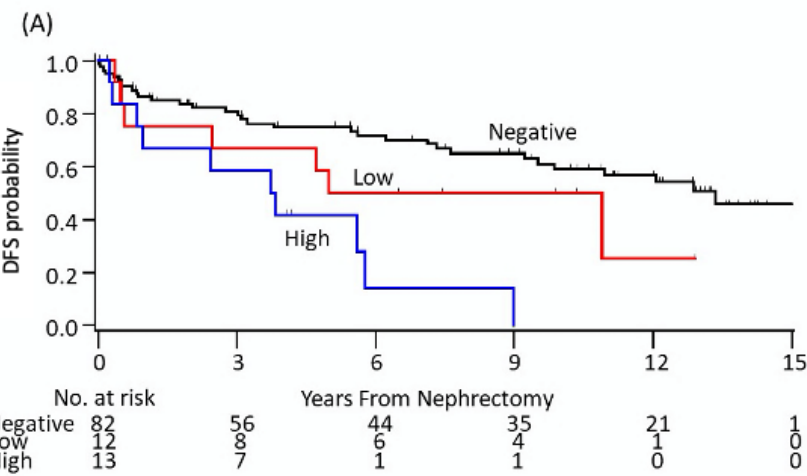

(B)

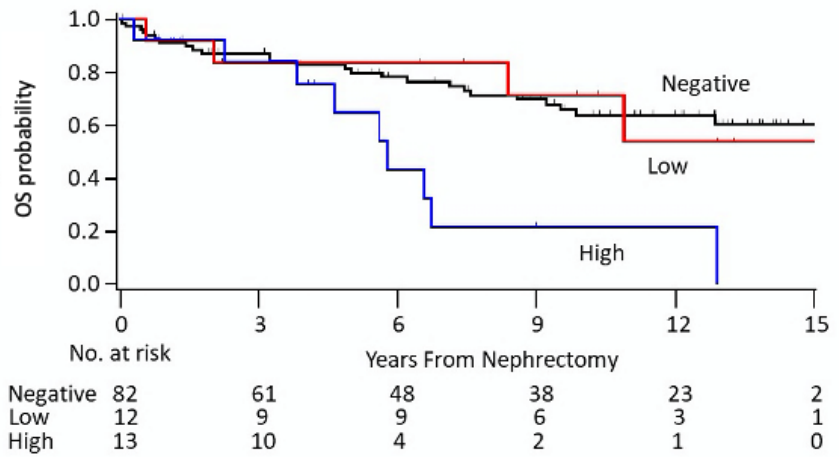

Figure 3 Kaplan-Meier plots of (A) DFS and (B) OS according to CD73 expression in patients with localized renal cell carcinoma. DFS, disease-free survival; OS, overall survival.

role. $^{23-26}$ Approximately 5\%-30\% of non-ccRCCs express PD-L1, and PD-1/-L1 blockade has demonstrated encouraging efficacy in non-clear cell histologies with an ORR of approximately 25\%. ${ }^{23}$ Similarly, the presence of sarcomatoid differentiation has been associated with increased responsiveness to immune checkpoint inhibition. ${ }^{2526}$ The CD73-adenosine pathway could be a complementary therapeutic target in these histological subtypes where there exists an even greater clinical need for more effective therapies. We observed CD73 positivity in 39\% of our non-ccRCC samples with 24\% demonstrating high CD73 expression. In our dataset, $90 \%$ of tumors with a sarcomatoid component demonstrated CD73 expression, and $50 \%$ were $\mathrm{CD} 73_{\text {high }}$. Although limited by the small sample sizes and in need of validation, to our knowledge, this is the first study characterizing CD73 expression in nonclear cell and sarcomatoid RCC.

In the TCGA dataset, we also found a strong correlation between CD73 (NT5E), CD39 (ENTPD1) and A2AR (ADORA2A) expression, and Treg gene expression signature. CD73 and CD39 activation on tumor and stromal cells generates extracellular adenosine, which exerts an immunosuppressive effect antagonistic to PD-1 inhibitors. Adenosine activates the high-affinity A2AR receptor, which in turn inhibits infiltrating NK cells and cytotoxic T lymphocyte activity and increases Treg proliferation. ${ }^{11}$ 27-30 In addition to tumor cells, CD73, CD39, and

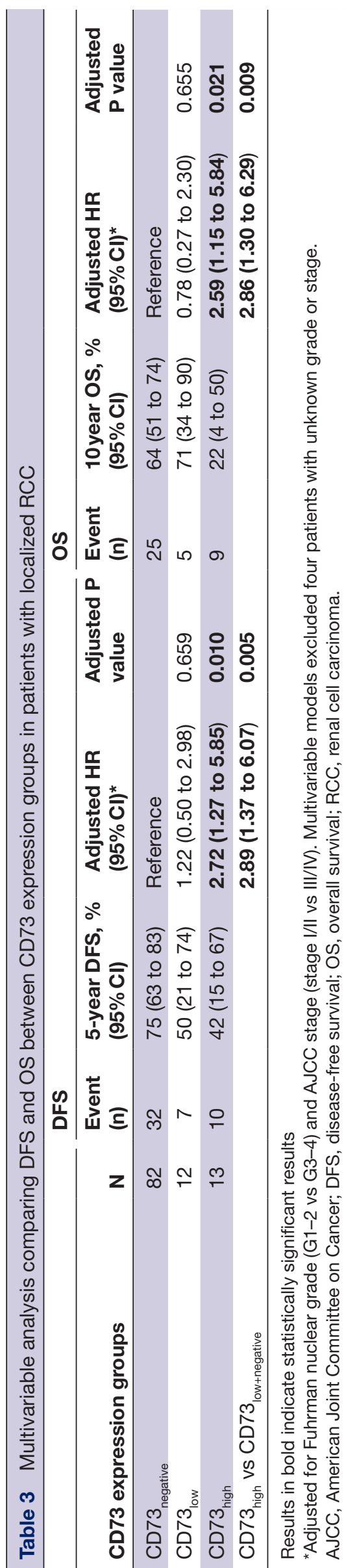



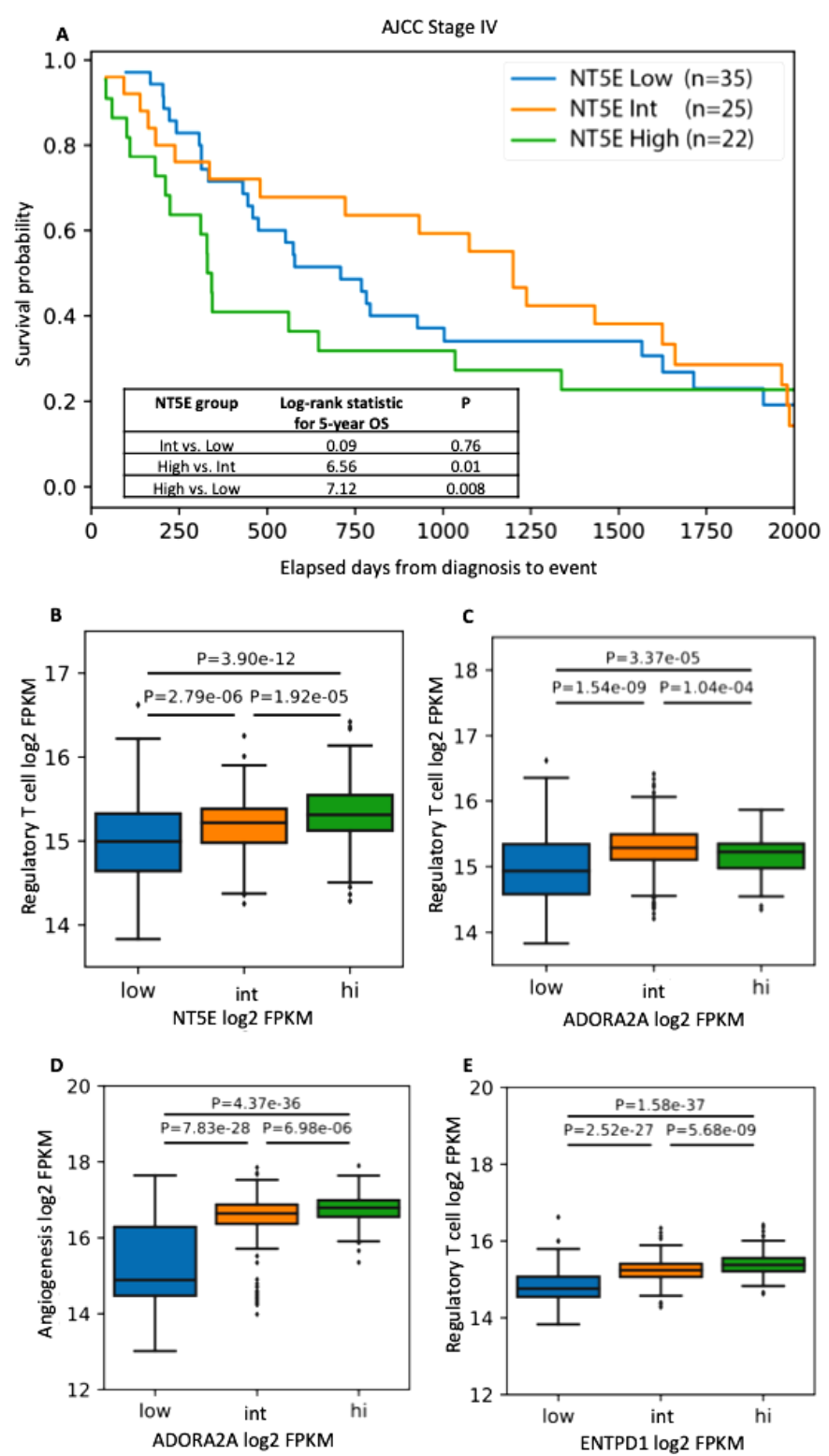

Figure 4 Genomic and clinical correlates of CD73 (NT5E), A2aR (ADORA2A) and CD39 (ENTPD1) gene expression in the TCGA cohort. AJCC, American Joint Committee on Cancer; FPKM, fragments per kilobase million; Int, intermediate; OS, overall survival.

A2AR can also be expressed on infiltrating immune cells such as Tregs and effector T cells with resultant autocrine production of adenosine further promoting immunosuppression through Treg proliferation. ${ }^{27} 31$ The strong correlation of NT5E, ENTPD1, and ADORA2A expression with the Treg signature observed in our analysis supports the findings of prior preclinical studies ${ }^{11}$ and provides additional mechanistic support for the immunosuppressive role of CD73-adenosine signaling in RCC.

Adenosine signaling also mediates the recruitment and proliferation of granulocytic MDSCs. ${ }^{12}$ Fong et al reported that a gene expression signature incorporating genes encoding CXCR2 ligands (eg, CXCL1, CXCL2, CXCL3, CXCL5, and CXCL6) and mediators of neutrophil and MDSC biology (ILB, IL1B, and PTGS2) could be a potential biomarker of CD73-adenosine signaling. ${ }^{32}$ The myeloid-inflammation gene signature used in our study includes several genes included in the adenosine signature (CXCL1, CXCL2, CXCL3, CXCL8, and PTGS2). However, we did not find a correlation between NT5E expression and myeloid inflammation gene expression signature. Further, there was no significant difference in MDSC signature between low and high NT5E expression groups $(\mathrm{p}=3.50 \mathrm{E}-01)$. It is possible that $\mathrm{CD} 73$ protein expression or cell type-specific expression (tumor vs immune cell) might have differential effects on these signatures, which was not captured in the bulk RNA-seq data derived from the TCGA dataset.

Preclinical evidence also suggests that CD73-adenosine signaling may promote angiogenesis through vasodilation, release of proangiogenic factors such as VEGF, and recruitment of endothelial progenitor cells. ${ }^{14-16}$ While we did not observe a correlation between NT5E expression and angiogenesis marker genes, high expression of $A D O R A 2 A$ was strongly associated with high angiogenesis gene expression signature. Dysregulation of the proangiogenic HIF pathway is a critical oncogenic driver in RCC, and A2AR has been identified as a downstream proangiogenic target unique to HIF-2 $\alpha .{ }^{33}{ }^{34}$ A2AR activation can result in increased angiogenesis through decreased secretion of thrombospondin-1 (TSP-1) and by promoting differentiation of macrophages to the M2 phenotype resulting in increased expression of proangiogenic factors such as VEGF, IL-10 and nitric oxide synthase. ${ }^{35-37}$ Our findings, in corroboration with mechanistic insights from preclinical studies, ${ }^{11} 2829343839$ support the hypothesis that adenosine signaling contributes to both tumor immune evasion and angiogenesis in RCC.

Several agents targeting the CD73-adenosine pathway are in clinical development either as monotherapy or in combination with approved anti-PD-1/L1 agents across several cancers, including mRCC. In a first in human, phase I dose-escalation study, the oral competitive A2AR inhibitor ciforadenant (CPI-444) was evaluated as monotherapy and in combination with atezolizumab in patients with advanced refractory cancers. ${ }^{32}$ Among patients with treatment-refractory mRCC, ciforadenant demonstrated encouraging efficacy, and disease control lasting at least 6 months was seen in $39 \%$ of patients treated with the combination. Multiple ongoing trials are investigating adenosine pathway blockade via inhibition of CD73, A2AR, and CD39 as monotherapy and combinations (eg, NCT04148937, NCT03549000, NCT03454451, NCT03835949, NCT03884556, NCT03381274, and NCT04336098). Evaluation of predictive biomarkers such as CD73 expression or adenosine pathway gene expression signatures has the potential to optimize patient selection.

Our study has limitations inherent to institutional retrospective analyses. The relatively small number of patients with non-clear cell histology and de novo mRCC limited our investigation of the prognostic significance of CD73 expression in these subgroups. CD73 expression on 
stromal cells or infiltrating immune cells was not assessed, which could provide additional insights into the role of CD73-adenosine signaling in the tumor microenvironment. Although our analysis demonstrates that CD73 expression is associated with poor prognosis at both the mRNA and protein level, additional experimentation will be required to determine the correlation between $\mathrm{CD} 73$ protein and mRNA expression. Lastly, protein expression of A2AR and CD39 was not assessed in the current dataset but is worthy of future study of optimal biomarker signatures for adenosine signaling in RCC.

\section{CONCLUSIONS}

The CD73-adenosine pathway is an emerging therapeutic target in RCC with extensive preclinical data and growing clinical evidence supporting its role in immunosuppression and angiogenesis. We found that a significant proportion of both clear cell and non-ccRCC tumors express CD73 with a propensity for higher expression in de novo $\mathrm{mRCC}$ and sarcomatoid tumors. Higher expression correlated with worse DFS and OS in patients with localized disease independent of stage and grade. In addition, gene expression of CD73, CD39 and A2AR was associated with increased immunosuppressive cell markers and while A2AR expression correlated with the angiogenesis signature in the TCGA cohort. Our findings support the growing investigation of this pathway in advanced RCC.

\author{
Author affiliations \\ ${ }^{1}$ University of Oklahoma Health Sciences Center, Stephenson Cancer Center, \\ Oklahoma City, Oklahoma, USA \\ ${ }^{2}$ Lank Center for Genitourinary Oncology, Dana-Farber Cancer Institute, Boston, \\ Massachusetts, USA \\ ${ }^{3}$ University of Utah, Huntsman Cancer Institute, Salt Lake City, Utah, USA \\ ${ }^{4}$ Department of Data Sciences, Dana Farber Cancer Institute, Boston, \\ Massachusetts, USA \\ ${ }^{5}$ Brigham and Women's Hospital, Boston, Massachusetts, USA \\ ${ }^{6}$ Beth Israel Deaconess Medical Center, Boston, Massachusetts, USA \\ ${ }^{7}$ Oklahoma Medical Research Foundation, Oklahoma City, Oklahoma, USA \\ ${ }^{8}$ Dana-Farber Cancer Institute, Boston, Massachusetts, USA
}

Twitter Abhishek Tripathi @AbhiTrip87, Toni K Choueiri @DrChoueiri and Lauren C Harshman @LaurenCHarshman

Acknowledgements We thank Abhishek A Chakraborty, PhD, at the Cleveland Clinic's Lerner College of Medicine for providing the Von Hippel-Lindau (VHL) proficient and deficient UMRC2 cells used for positive and negative controls for the immunohistochemistry.

\section{Funding NCI SPORE Grant no: P50 CA101942.}

Competing interests AT: advisory role for Foundation Medicine, Pfizer; research funding to institution from EMD Serono, Bayer, Clovis Oncology, Aravive Inc, WindMIL therapeutics, Corvus Pharmaceuticals; EL, WX, AF, JAS, ESG, GB, JHF, CG, CM and LT: none; NM-C: support for research travel from Pfizer and Ipsen, and consulting fees from BMS and Bayer; XXW: research funding to institution from Bristol-Myers Squibb (BMS); MG: research funding from BMS and Merck; BAM: payment for consulting with Bayer, Astellas, Astra Zeneca, Seattle Genetics, Exelixis, Nektar, Pfizer, Janssen, Genentech, Eisai and EMD Serono, and received research support to Dana Farber Cancer Institute (DFCl) from BMS, Calithera, Exelixis, Seattle Genetics. TKC: supported in part by the Dana-Farber/Harvard Cancer Center Kidney SPORE and Program, the Kohlberg Chair at Harvard Medical School and the Trust Family, Michael Brigham, and Loker Pinard Funds for Kidney Cancer Research at DFCI. Research (institutional and personal): AstraZeneca, Alexion, Bayer, BMS/ ER Squibb and sons LLC, Cerulean, Eisai, Foundation Medicine Inc, Exelixis,
Ipsen, Tracon, Genentech, Roche, Roche Products Limited, F. Hoffmann-La Roche, GlaxoSmithKline, Lilly, Merck, Novartis, Peloton, Pfizer, Prometheus Labs, Corvus, Calithera, Analysis Group, Sanofi/Aventis, Takeda. Honoraria: AstraZeneca, Alexion, Sanofi/Aventis, Bayer, BMS/ER Squibb and sons LLC, Cerulean, Eisai, Foundation Medicine Inc, Exelixis, Genentech, Roche, Roche Products Limited, F. Hoffmann-La Roche, GlaxoSmithKline, Merck, Novartis, Peloton, Pfizer, EMD Serono, Prometheus Labs, Corvus, Ipsen, Up-to-Date, NCCN, Analysis Group, NCCN, Michael J. Hennessy (MJH) Associates, Inc (Healthcare Communications Company with several brands such as OnClive, PeerView and PER), Research to Practice, L-path, Kidney Cancer Journal, Clinical Care Options, Platform Q, Navinata Healthcare, Harborside Press, American Society of Medical Oncology, NEJM, Lancet Oncology, Heron Therapeutics, Lilly Oncology. Consulting or advisory Role: AstraZeneca, Alexion, Sanofi/Aventis, Bayer, Bristol Myers-Squibb/ER Squibb and sons LLC, Cerulean, Eisai, Foundation Medicine Inc., Exelixis, Genentech, Heron Therapeutics, Lilly, Roche, GlaxoSmithKline, Merck, Novartis, Peloton, Pfizer, EMD Serono, Prometheus Labs, Corvus, Ipsen, Up-to-Date, NCCN, Analysis Group, Pionyr, Tempest, Lilly Ventures. Stock ownership: Pionyr, Tempest. Other present or past leadership roles: Director of GU Oncology Division at Dana-Farber and past President of medical Staff at Dana-Farber), member of NCCN Kidney panel and the GU Steering Committee, past chairman of the Kidney Cancer Association Medical and Scientific Steering Committee), KidneyCan Advisory board, Kidney cancer Research Summit co-chair (2019-). Patents, royalties or other intellectual properties: related to biomarkers of immune checkpoint blockers. Travel, accommodations, expenses, in relation to consulting, advisory roles, or honoraria: Medical writing and editorial assistance support may have been funded by Communications companies funded by pharmaceutical companies (ClinicalThinking, Envision Pharma Group, Fishawack Group of Companies, Health Interactions, Parexel, Oxford PharmaGenesis, and others).The institution (Dana-Farber Cancer Institute) may have received additional independent funding of drug companies or/and royalties potentially involved in research around the subject matter. CV provided upon request for scope of clinical practice and researchMentored several non-US citizens on research projects with potential funding (in part) from non-US sources/Foreign Components. NA: consultancy to Astellas, Astra Zeneca, Bayer, Bristol Myers Squibb, Clovis, Eisai, Eli Lilly, EMD Serono, Exelixis, Foundation Medicine, Genentech, Janssen, Merck, Nektar, Novartis, Pfizer, Pharmacyclics, and Seattle Genetics. Research funding to my institution: Astra Zeneca, Bavarian Nordic, Bayer, Bristol Myers Squibb, Calithera, Celldex, Clovis, Eisai, Eli Lilly, EMD Serono, Exelixis, Genentech, Glaxo Smith Kline, Immunomedics, Janssen, Medivation, Merck, Nektar, New Link Genetics, Novartis, Pfizer, Prometheus, Rexahn, Roche, Sanofi, Seattle Genetics, Takeda, and Tracon. DFM: Honorarium for consultancy from BMS, Pfizer, Merck, Alkermes Inc, EMD Serono, Eli Lilly, lovance and Eisai. Research support from BMS, Merck, Genentech, Pfizer, Exelixis, X4 Pharma, Alkermes. SS: reports receiving commercial research grants from Bristol-Myers Squibb, AstraZeneca, Exelixis and Novartis; is a consultant/advisory board member for Merck, AstraZeneca, Bristol-Myers Squibb, CRISPR Therapeutics AG, AACR, and NCl; and receives royalties from Biogenex. LCH: Reports consulting fees from Genentech, Dendreon, Pfizer, Medivation/ Astellas, Exelixis, Bayer, Kew Group, Corvus, Merck, Novartis, BMS, Michael J Hennessy Associates (Healthcare Communications Company and several brands such as OncLive and PER), Jounce, EMD Serrano, ASIM CME, and Ology Medical Education. Research funding from Bayer, Sotio, BMS, Merck, Takeda, Dendreon/ Valient, Jannsen, Medivation/Astellas, Genentech, Pfizer, Endocyte (Novartis). Support for research travel from Bayer and Genentech. Currently employed by Surface Oncology.

\section{Patient consent for publication Not required.}

Ethics approval Institutional ethics committee approval was obtained.

Provenance and peer review Not commissioned; externally peer reviewed.

Data availability statement All data relevant to the study are included in the article or uploaded as supplementary information. The datasets generated during and/or analyzed during the current study are available from the corresponding author on request.

Supplemental material This content has been supplied by the author(s). It has not been vetted by BMJ Publishing Group Limited (BMJ) and may not have been peer-reviewed. Any opinions or recommendations discussed are solely those of the author(s) and are not endorsed by BMJ. BMJ disclaims all liability and responsibility arising from any reliance placed on the content. Where the content includes any translated material, BMJ does not warrant the accuracy and reliability of the translations (including but not limited to local regulations, clinical guidelines, terminology, drug names and drug dosages), and is not responsible for any error and/or omissions arising from translation and adaptation or otherwise. 
Open access This is an open access article distributed in accordance with the Creative Commons Attribution 4.0 Unported (CC BY 4.0) license, which permits others to copy, redistribute, remix, transform and build upon this work for any purpose, provided the original work is properly cited, a link to the licence is given, and indication of whether changes were made. See https://creativecommons.org/ licenses/by/4.0/.

\section{ORCID iDs}

Abhishek Tripathi http://orcid.org/0000-0002-5198-0673

Nieves Martinez-Chanza http://orcid.org/0000-0002-2340-7415

Toni K Choueiri http://orcid.org/0000-0002-9201-3217

Neeraj Agarwal http://orcid.org/0000-0003-1076-0428

Lauren C Harshman http://orcid.org/0000-0002-7636-1588

\section{REFERENCES}

1 Motzer RJ, Tannir NM, McDermott DF, et al. Nivolumab plus ipilimumab versus sunitinib in advanced renal-cell carcinoma. $N$ Eng J Med 2018;378:1277-90.

2 Tannir NM, Frontera OA, Hammers HJ, et al. Thirty-month followup of the phase III CheckMate 214 trial of first-line nivolumab + ipilimumab $(\mathrm{N}+\mathrm{l})$ or sunitinib (S) in patients (PTS) with advanced renal cell carcinoma (aRCC). JCO 2019;37:547.

3 Rini BI, Plimack ER, Stus V, et al. Pembrolizumab plus axitinib versus sunitinib for advanced renal-cell carcinoma. $N$ Engl J Med 2019;380:1116-27.

4 Motzer RJ, Penkov K, Haanen J, et al. Avelumab plus axitinib versus sunitinib for advanced renal-cell carcinoma. $N$ Engl J Med 2019;380:1103-15

5 Zimmermann H. 5'-Nucleotidase: molecular structure and functional aspects. Biochem J 1992;285 (Pt 2:345-65.

6 Sitkovsky MV, Kjaergaard J, Lukashev D, et al. Hypoxiaadenosinergic immunosuppression: tumor protection by $T$ regulatory cells and cancerous tissue hypoxia. Clin Cancer Res 2008;14:5947-52.

7 Synnestvedt K, Furuta GT, Comerford KM, et al. Ecto-5'Nucleotidase (CD73) regulation by hypoxia-inducible factor- 1 mediates permeability changes in intestinal epithelia. J Clin Invest 2002;110:993-1002.

8 Semenza GL. Hypoxia-Inducible factors in physiology and medicine. Cell 2012;148:399-408.

9 Yegutkin GG. Nucleotide- and nucleoside-converting ectoenzymes: important modulators of purinergic signalling cascade. Biochim Biophys Acta 2008;1783:673-94.

10 Takayama H, Trenn G, Sitkovsky MV. Locus of inhibitory action of cAMP-dependent protein kinase in the antigen receptortriggered cytotoxic T lymphocyte activation pathway. J Biol Chem 1988;263:2330-6.

11 Ohta A, Kini R, Ohta A, et al. The development and immunosuppressive functions of CD4(+) CD25(+) FoxP3(+) regulatory $\mathrm{T}$ cells are under influence of the adenosine-A2A adenosine receptor pathway. Front Immunol 2012;3:190.

12 Ryzhov S, Novitskiy SV, Goldstein AE, et al. Adenosinergic regulation of the expansion and immunosuppressive activity of CD11b+Gr1+ cells. J Immunol 2011;187:6120-9.

13 Csóka B, Selmeczy Z, Koscsó B, et al. Adenosine promotes alternative macrophage activation via $\mathrm{A} 2 \mathrm{~A}$ and $\mathrm{A} 2 \mathrm{~B}$ receptors. Faseb J 2012;26:376-86.

14 Smits P, Williams SB, Lipson DE, et al. Endothelial release of nitric oxide contributes to the vasodilator effect of adenosine in humans. Circulation 1995;92:2135-41.

15 Feoktistov I, Ryzhov S, Zhong H, et al. Hypoxia modulates adenosine receptors in human endothelial and smooth muscle cells toward an A2B angiogenic phenotype. Hypertension 2004;44:649-54.

16 Montesinos MC, Shaw JP, Yee $\mathrm{H}$, et al. Adenosine $\mathrm{A}(2 \mathrm{~A})$ receptor activation promotes wound neovascularization by stimulating angiogenesis and vasculogenesis. Am J Pathol 2004;164:1887-92.

17 Tripathi A, Johnston SE, Zhao YD, et al. CD73 expression in primary and metastatic renal cell carcinoma (RCC). Journal of Clinical Oncology 2018;36:643.
18 Cancer Genome Atlas Research Network. Comprehensive molecular characterization of clear cell renal cell carcinoma. Nature 2013;499:43-9.

19 Anders S, Pyl PT, Huber W. HTSeq--a Python framework to work with high-throughput sequencing data. Bioinformatics 2015;31:166-9.

20 McDermott DF, Huseni MA, Atkins MB, et al. Clinical activity and molecular correlates of response to atezolizumab alone or in combination with bevacizumab versus sunitinib in renal cell carcinoma. Nat Med 2018;24:749-57.

21 Charoentong $\mathrm{P}$, Finotello F, Angelova M, et al. Pan-Cancer Immunogenomic analyses reveal Genotype-Immunophenotype relationships and predictors of response to checkpoint blockade. Cell Rep 2017;18:248-62.

$22 \mathrm{Yu}$ YI, Wang W, Song L, et al. Ecto-5'-Nucleotidase expression is associated with the progression of renal cell carcinoma. Oncol Lett 2015;9:2485-94.

23 Choueiri TK, Fay AP, Gray KP, et al. PD-L1 expression in nonclear-cell renal cell carcinoma. Ann Oncol 2014;25:2178-84.

24 McGregor BA, McKay RR, Braun DA, et al. Results of a multicenter phase II study of Atezolizumab and bevacizumab for patients with metastatic renal cell carcinoma with variant histology and/or Sarcomatoid features. J Clin Oncol 2020;38:63-70.

25 Rini BI, Huseni M, Atkins MB, et al. Molecular correlates differentiate response to atezolizumab (atezo) + bevacizumab (bev) vs sunitinib (sun): results from a phase III study (IMmotion151) in untreated metastatic renal cell carcinoma (mRCC). Annals of Oncology 2018;29:viii724-5.

26 McDermott DF, Choueiri TK, Motzer RJ, et al. CheckMate 214 posthoc analyses of nivolumab plus ipilimumab or sunitinib in IMDC intermediate/poor-risk patients with previously untreated advanced renal cell carcinoma with sarcomatoid features. JCO 2019;37:4513.

27 Chambers AM, Wang J, Lupo KB, et al. Adenosinergic signaling alters natural killer cell functional responses. Front Immunol 2018;9:2533.

28 Sitkovsky MV, Lukashev D, Apasov S, et al. Physiological control of immune response and inflammatory tissue damage by hypoxiainducible factors and adenosine A2A receptors. Annu Rev Immunol 2004;22:657-82.

29 Clayton A, Al-Taei S, Webber J, et al. Cancer exosomes express CD39 and CD73, which suppress T cells through adenosine production. J Immunol 2011;187:676-83.

30 Wang L, Fan J, Thompson LF, et al. CD73 has distinct roles in nonhematopoietic and hematopoietic cells to promote tumor growth in mice. J Clin Invest 2011;121:2371-82.

31 Deaglio S, Dwyer KM, Gao W, et al. Adenosine generation catalyzed by CD39 and CD73 expressed on regulatory $T$ cells mediates immune suppression. J Exp Med 2007;204:1257-65

32 Fong L, Hotson A, Powderly JD, et al. Adenosine 2A receptor blockade as an immunotherapy for treatment-refractory renal cell cancer. Cancer Discov 2020;10:40-53.

33 Ricketts CJ, Crooks DR, Linehan WM. Targeting HIF2 $\alpha$ in clear-cell renal cell carcinoma. Cancer Cell 2016;30:515-7.

34 Ahmad A, Ahmad S, Glover L, et al. Adenosine A2A receptor is a unique angiogenic target of HIF-2alpha in pulmonary endothelial cells. Proc Natl Acad Sci U S A 2009;106:10684-9.

35 Desai A, Victor-Vega C, Gadangi S, et al. Adenosine A2A receptor stimulation increases angiogenesis by down-regulating production of the antiangiogenic matrix protein thrombospondin 1. Mol Pharmacol 2005;67:1406-13.

36 Ferrante CJ, Pinhal-Enfield G, Elson G, et al. The adenosinedependent angiogenic switch of macrophages to an M2-like phenotype is independent of interleukin-4 receptor alpha (IL-4R $\alpha$ ) signaling. Inflammation 2013;36:921-31.

37 Grinberg S, Hasko G, Wu D, et al. Suppression of PLCbeta2 by endotoxin plays a role in the adenosine $A(2 A)$ receptor-mediated switch of macrophages from an inflammatory to an angiogenic phenotype. Am J Pathol 2009;175:2439-53.

38 Ohta A, Gorelik E, Prasad SJ, et al. A2A adenosine receptor protects tumors from antitumor T cells. Proc Natl Acad Sci U S A 2006;103:13132-7.

39 Csóka B, Himer L, Selmeczy Z, et al. Adenosine A2A receptor activation inhibits $T$ helper 1 and $T$ helper 2 cell development and effector function. Faseb J 2008;22:3491-9. 